\title{
Con pan y vino se anda el camino. Los viajes en la Castilla medieval
}

\author{
$M^{a}$ Jesús Fuente PÉREZ
}

Los viajes son y han sido actividad importante en la vida de los hombres de todos los tiempos. Por necesidad o por afán de aventuras el hombre se ha movido en ámbitos más o menos alejados de su lugar de procedencia desde tiempos remotos, y si el viaje de placer es algo relativamente reciente, el "viaje de negocios" es tan viejo como la propia historia del hombre 1.

Gracias a los relatos de viajeros se han llegado a conocer aspectos diversos de nuestra historia. Los relatos y referencias de viajes son, sin duda, una fuente histórica importante en la que se han basado buena parte de los trabajos que se han realizado sobre los viajes medievales, al menos los considerados más importantes: las grandes peregrinaciones a Santiago de Compostela o a Roma ${ }^{2}$, los viajes de los cruzados a Tierra Santa, las expediciones de mercaderes italianos o hanseáticos, etc. Sin embargo, algunos aspectos de las rutas, de los medios de transporte, de los albergues, etc. se conocen menos a través de los relatos de viajeros que estudiando otras fuentes ${ }^{3}$. Los documentos judiciales y municipales o los textos literarios son las fuentes en las que hay que indagar para conseguir información complementaria que permita conocer el mundo del viajero medieval.

Este artículo pretende dar a conocer algunos aspectos de la vida de ese viajero medieval, pero desde una perspectiva diferente. Si se han

El interés del estudio de los viajes en el pasado, como precedentes del moderno fenómeno del turismo es discutido en Valence L. SMITH, "Hosts and Guests revisited", American Behavioral Scientist, nov.- dic. 1992, pág. 187 y ss.

2 Y. RenOuARD, «Routes, étapes et vitesses de marche de France a Rome au XIII et au XIV siecle d'apres les itinéraires d'Eudes Rigaud (1254) et de Barthélemy Bonis (1350)", Studi in onore di Amintore Fanfani, Milan, 1962, vol. III, pp. 405-428.

3 María Desamparados Sánchez Villar, Desde Estella a Sevilla: Cuentas de un viaje (1352), Valencia, 1962. El itinerario transcrito en este trabajo fue tomado del Archivo General de Navarra, Comptos. 
estudiado principalmente los viajes extraordinarios, se quiere aquí mostrar simplemente los viajes ordinarios. Si se ha dado cuenta de los viajes de personajes famosos, se quiere aquí indagar acerca del viajero anónimo. Para ello se va a utilizar una única fuente, los documentos municipales, y en concreto las cuentas. Simplemente con esta fuente se pueden mostrar las posibilidades de la documentación con referencias a viajes para estudiar algunos aspectos de la vida cotidiana: la comida, los caminos, los gastos de viaje y las costumbres con ellos relacionadas.

La documentación utilizada son las cuentas de los procuradores del concejo de Paredes de Nava. Hay en estas cuentas continuas referencias a viajes de mensajeros enviados a resolver asuntos a diversos lugares, a la corte del Rey, a la corte del señor de la villa, al obispado, etc. En ocasiones, con motivo de pleitos o asuntos de mayor envergadura, hay cuenta detallada de los gastos que se hicieron en viajes más largos en espacio y tiempo. Seleccionando algunos de estos viajes puede darse una visión interesante del mundo de los viajeros castellanos, de sus itinerarios, sus costumbres, sus comidas, sus gastos, etc. Los dos viajes escogidos son los que realizaron con motivo de dos problemas que le surgieron al concejo, uno por razón de un pleito entre los años 1414 y 1417, y otro por problemas con el señor y el corregidor en el año 1403. Vamos a utilizar en primer lugar y especialmente la referencia a los viajes con motivo del pleito, y en segundo lugar los viajes de 1403 que añaden alguna información más. El conjunto de los viajes de esos años ofrece un panorama amplio y complementario, porque si muchos ofrecen la imagen del mundo ordinario, otros indican algunos aspectos de lo extraordinario.

\section{LAS RAZONES DEL VIAJE}

Entre los años 1414 y 1417 el concejo paredeño se vio envuelto en un pleito algo sorprendente. La sorpresa se produce porque en su origen ese pleito no atañía a la autoridad municipal, sino que era el resultado de las desavenencias entre el arciprestazgo de Paredes y el Obispo de Palencia. El primero quería intervenir en los pleitos de costo superior a los 60 maravedíes que le tenía limitado el Obispado, y se saltó la norma en alguna ocasión. Como consecuencia se planteó un pleito por razón de la jurisdicción, que curiosamente hizo suyo el concejo representando al vicario del arciprestazgo de Paredes, de manera que todas las gestiones que se hicieron para resolverlo enfrentaron de un lado al Obispo de Palencia y del otro al concejo de Paredes. Es por ello por lo que las autoridades municipales enviaron a sus representantes a tratar con el Papa 
en dos ocasiones ${ }^{4}$. En esos mismos viajes también se menciona la visita al Rey de Aragón(D. FERnANDo DE ANTEQUERA, señor de la villa de Paredes). El Papa ordena que como juez árbitro actúe el abad del monasterio de Santa María de Aguilar de Campoo, por lo que en varias ocasiones (hay referencias a ocho viajes) los representantes del concejo paredeño tienen que desplazarse a esa localidad en el Norte de la provincia para tratar con el abad. El pleito les lleva también a Salamanca a recibir consejo de abogado, y a otras localidades (Palencia, Valladolid, etc.) para resolver otros asuntos menores.

Las referencias a todos los viajes ofrecen datos interesantes, pero seis de ellos son de especial interés por aparecer anotadas las cuentas con todo detalle: uno a Perpiñán, otro a Salamanca y cuatro a Aguilar. Están tan pormenorizados que permiten ofrecer un buen panorama de lo que debian ser esos "viajes de negocios" medievales.

Lo mismo podría decirse de los viajes de 1403. En el mes de enero de ese año, varios hombres del concejo de Paredes hicieron dos viajes en relación çon un mismo asunto: solicitar el perdón del infante. Algunos problemas se habían desarrollado en esta villa, cuando se habla de "muertos" y de un corregidor, que habría sido enviado a la localidad para poner fin a esos problemas, y finalmente se habla de perdón.

Con motivo de este asunto hacen un viaje a Palencia, a tratar con el ${ }^{\text {. }}$ Obispo sobre el perdón. Pero este viaje duró sólo dos días, 26 y 27 de enero de 1403. El viaje más largo fue el que realizaron a Medina del Campo, iniciado dos días después de volver de Palencia, el 29 de enero. Realizaron este viaje 20 hombres y "quinse bestias».

\section{PREPARATIVOS DE VIAJE: LOCOMOCIÓN E ITINERARIOS}

Hablar de preparativos en los viajes medievales puede parecer exagerado. Sus posibilidades de organizar un viaje eran, sin duda, muy limitadas. Faltan referencias a preparativos, pero se puede suponer que no harían el viaje sin un mínimo de conocimiento del camino, de los gastos previstos e imprevistos, y de todas aquellas cosas que estuvieran a su alcance.

Desde el lugar de partida preparaban la caballería o caballerías requeridas: mula, caballo o rocín, según el tipo de viaje o las posibilidades de alquiler que hubiera. Posiblemente no hicieran viajes largos en un rocín, por necesitar caballerías jóvenes y briosas, que resistieran largas jornadas, sin

4 La visita al Papa se realiza en Montblanc en el primer viaje y en Perpiñan en el segundo. 
ocasionar otro problema más que el del cambio de herradura. Tomaban la precaución de herrarlas antes de salir de viaje, y sólo en los viajes largos tenían que parar de nuevo en casa del herrador.

También necesitaban preparar itinerarios, especialmente cuando se trataba de viajes largos, pues los caminos más cortos o frecuentados posiblemente los conocían suficientemente bien. Los preparativos del camino tampoco podrían hacerse con gran minuciosidad, de manera que las paradas para comer o dormir no se ajustaban a un número de kilómetros regular, debido posiblemente a factores diversos: hora del día a la que se pusieran en camino, necesidad de descanso, posibilidades de encontrar posada, gestiones a realizar en el camino, o imprevistos de otro tipo ${ }^{5}$.

Las pocas posibilidades de preparación explican los imprevistos frecuentes a los que tienen que enfrentarse los viajeros. En uno de los viajes del pleito que nos ocupa, el procurador, Gonçalo Ferrandes Ollero, se demora tres días en Soria para resolver un asunto, de manera que no llega a tiempo a Morella, donde esperaba encontrar al Papa y al Rey ${ }^{6}$.

De este primer viaje a la corte papal, que duró tres meses y.cuatro días, no hay muchos datos. El más rico de información es el segundo a la corte papal (esta vez a Perpiñán), aunque fue un viaje más corto, duró sólo 54 días. El itinerario seguido fue Aranda, El Burgo, Soria, puerto de Deza, Cervera, Gerona y Perpiñán.

En los viajes cortos tenían más posibilidades de realizar un itinerario fijo y posiblemente bien conocido de antemano. En efecto, el itinerario de los viajes de Aguilar de Campoo era casi siempre el mismo. Puede servir como ejemplo el viaje que realizaron entre los días 16 y 22 de enero de 1415: Paredes, Amusco, Fromista, Santillana, Herrera, S, Vicente y Aguilar. La vuelta la hicieron por un itinerario diferente: Aguilar, S. Esteban, Villavermudo, Castrillo de Villavega, Carrión y Paredes de Nava.

En los viajes a Salamanca el itinerario de ida también era diferente del de vuelta. El que realizaron en el mes de abril de 1415 partió de Paredes y recorrió Medina de Rioseco, Urueña, Toro, La Bóveda, Fuentesauco, Villanueva y Salamanca, haciendo el regreso por Villoruela, Cantalpino, Cantalapiedra, Medina del Campo, Puente de Duero, Valladolid, Ampudia y Paredes.

5 En el viaje de vuelta de Sevilla a Estella, tienen que cambiar el ritmo del trayecto porque uno de los viajeros se ha puesto enfermo. Maria Desamparados Sánchez Villar, Desde Estella a Sevilla pp. 74-77.

6 E. SARASA, "La mesa viajera del rey de Aragón Fernando l», Historia 16, 223, nov. 1994, pág. 87. Informa de la reunión que mantuvieron en Morella, en el mes de julio de 1414 Fernando I de Aragón y el papa Benedicto XIII. El mensajero de Paredes no llegó a Morella hasta el 11 de setiembre. 
Estos itinerarios plantean algunas cuestiones: ¿Cuántos kilómetros recorrían diariamente?, ¿Cómo dividían la jornada? Para intentar dar respuesta a estas preguntas, vamos a estudiar más detalladamente uno de los itinerarios del viaje de ida y vuelta a Aguilar de Campoo, y otro del viaje a Salamanca.

\section{CUADRO 1 \\ ETAPAS DEL VIAJE A AGUILAR DE CAMPOO}

\begin{tabular}{|c|c|c|c|c|}
\hline \multicolumn{5}{|c|}{ Itinerario de ida } \\
\hline Día & Itinerario & Kms. & Motivo parada & Total kms. \\
\hline 1 & $\begin{array}{l}\text { Paredes-Amusco } \\
\text { Amusco-Fromista } \\
\text { Fromista-Santillana }\end{array}$ & $\begin{array}{l}18 \\
12 \\
12\end{array}$ & $\begin{array}{l}\text { negocios } \\
\text { comida } \\
\text { posada }\end{array}$ & 42 \\
\hline 2 & $\begin{array}{l}\text { Santillana-Herrera } \\
\text { Herrera-S. Vicente }\end{array}$ & $\begin{array}{l}29 \\
14\end{array}$ & $\begin{array}{l}\text { comida } \\
\text { posada }\end{array}$ & 43 \\
\hline 3 & S. Vicente-Aguilar & 20 & & \\
\hline \multicolumn{5}{|c|}{ Itinerario de vuelta } \\
\hline Día & Itinerario & Kms. & Motivo parada & Total kms. \\
\hline 1 & $\begin{array}{l}\text { Aguilar-Villavermudo } \\
\text { Villavermudo-Castrillo }\end{array}$ & $\begin{array}{l}23 \\
21\end{array}$ & $\begin{array}{l}\text { comida } \\
\text { posada }\end{array}$ & 44 \\
\hline 2 & $\begin{array}{l}\text { Castrillo-Carrión } \\
\text { Carrión-Paredes }\end{array}$ & $\begin{array}{l}17 \\
21\end{array}$ & comida & 38 \\
\hline
\end{tabular}

CUADRO 2

ETAPAS DEL VIAJE A SALAMANCA

\begin{tabular}{c|l|c|c|c}
\hline \multicolumn{2}{c}{ Itinerario de ida } & \multicolumn{3}{c}{} \\
\hline Día & \multicolumn{1}{c}{ Itinerario } & Kms. & Motivo parada & Total kms. \\
\hline \multirow{2}{*}{1} & Paredes-Medina Rioseco & 24 & comida & \\
& Medina Rioseco-Urueña & 23 & posada & 47 \\
\hline \multirow{2}{*}{2} & Urueña-Toro & 18 & comida & \\
& Toro-La Bóveda & 21 & comida & \\
& La Bóveda-Fuentesauco & 15 & comida & \multirow{2}{*}{62} \\
& Fuentesauco-Villanueva & 18 & posada & \\
\hline \multirow{2}{*}{3} & Villanueva-Salamanca & 21 & & \\
\hline
\end{tabular}


Itinerario de vuelta

\begin{tabular}{c|c|c|c|c}
\hline Día & Itinerario & Kms. & Motivo parada & Total kms. \\
\hline \multirow{2}{*}{1} & Salamanca-Villoruela & 24 & comida & \\
& Villoruela-Cantalpino & 9 & posada & 33 \\
\hline \multirow{2}{*}{2} & Cantalpino-Cantalapiedra & 12 & comida & \\
& Cantalapiedra-Medina C. & 30 & comida & \multirow{2}{*}{ posada } \\
& Medina Campo-Puente D. & 32 & 74 \\
\hline \multirow{2}{*}{3} & Puente Duero-Valladolid & 11 & comida & \\
& Valladolid-Ampudia & 30 & comida & \multirow{2}{*}{69} \\
\hline
\end{tabular}

Las jornadas de viaje eran en general largas, el número de kilómetros que hacían cada día estaba en función de la luz solar que podían aprovechar. En enero (del 16 al 22), cuando efectuaron el viaje descrito a Aguilar, tenían muchas menos horas de luz que a mediados de abril (del 10 al 19 se realizó el viaje), cuando fueron a Salamanca, de manera que en enero hicieron una media de 40 kilómetros diarios aproximadamente, y en abril la media diaria ascendió a 60 kilómetros. Un mes después, en mayo, cuando realizaron otro viaje a Aguilar (del 9 al 18), la jornada de viaje fue aun mayor, de aproximadamente 80 kilómetros en un día, pues pudieron hacer el viaje entre Paredes y Aguilar sin pernoctar, aunque con varias paradas en el medio del camino para comer y beber. Estas etapas parecen estar en la linea de la velocidad de los correos profesionales a mediados del siglo XV, que ascendía a 60-70 kilómetros por día ${ }^{7}$, de 10 a 20 kilómetros más que en el siglo anterior, tal como se demuestra en los viajes estudiados por Renouard, y en el itinerario del viaje realizado en 1352 entre Estella y Sevilla. En este viaje, coincidiendo con los días largos de finales de mayo y primeros de junio hicieron una media de 52 kilometros diarios a la ida, y a la vuelta, en julio, de 48; la media total del viaje fue de 50 kilómetros diarios ${ }^{8}$.

Una de las cosas que llaman la atención es que los itinerarios de ida y vuelta eran diferentes, y no sólo en cuanto a los lugares que pasaban, sino a los kilómetros recorridos. La vuelta de Salamanca se hizo

7 Y. RenOUARD, op. cit. p. 428. Toma el dato de Giovanni di Antonio da Uzzano, Pratica della Mercatura.

8 Esta media diaria del viaje de Estella a Sevilla es la que indica Y. Renouaro como media del viajero ordinario a mediados del siglo XIV, op. cit. p. 428. 
recorriendo cuarenta kilómetros más. La vuelta de Aguilar, por el contrario, se hizo por un camino que les ahorró aproximadamente veinte kilómetros ${ }^{9}$.

¿Qué les llevaba a pararse en unos lugares y no en otros? Las paradas debían estar en relación con las localidades que hubiera en el camino, y de las posibilidades de encontrar posada en ellas, aunque en cualquier pueblo podrían encontrar alguien que les vendiera pan y vino. No faltaban las ocasiones en que el itinerario variaba por tener que realizar alguna gestión en alguna localidad en concreto.

\section{LOS GASTOS DE VIAJE}

Los viajes que nos sirven de ejemplo fueron realizados por enviados del concejo de Paredes de Nava. Se encomendaba el negocio a una persona, pero ésta normalmente no iba sola, llevaba un acompañante. Si el viajero era hombre prominente, llevaba consigo a un mozo o un criado.

No hay referencia a condiciones previas o acuerdos por ambas partes antes de emprender un viaje. Sólo se conoce que el concejo les asignaba una cantidad de dinero, que debía estar bastante bien calculada para que pudieran pagar los gastos que les fueran surgiendo. A la vuelta, el viajero daba cuenta pormenorizada de sus gastos y se le pagaba «el alcance» si había gastado más de lo previsto, o lo que se le había entregado no cubría gastos de viaje y pago de servicios ${ }^{10}$.

Los gastos eran de diversa índole, en primer lugar la comida y la posada de los viajeros, la alimentación de la caballería, los pagos de las costas del negocio que traían entre manos, invitaciones o regalos para aligerar los procesos, salarios de los viajeros, alquiler de las caballerías, y gastos imprevistos por vicisitudes que pudieran ir surgiendo.

g Modificaciones en parte del itinerario de regreso se comprueban también en el viaje citado Desde Estella a Sevilla.

10 En la cuenta del escribano y notario del concejo de Paredes de NAva, Alfons Ferrandes, fechada el 18 de marzo de 1403, anota un viaje de once dias que hizo a MEDinA junto a PERO GaRCia en el que el recibiría de salario «a mi e a la mula cada día ocho maravedies que monta ochenta e ocho maravedies e dieron nos PERO GonçALES procurador del conçejo para despender tresientos maravedíes e gastamos en estos honse dias nos e las bestias e FERRAND CANTARINO que fue con esto de pie en estos dias dosientos e çinquenta $e$ quatro maravedies asy fynca en mi quarenta e seys maravedies descontados de los ochenta e ocho maravedies he de aver de mi trabajo quarenta e dos maravedies". En Desde Estella a Sevilla se específica el dinero que reciben los viajeros antes de su partida, pp. 9-10. 
CUADRO 3

GASTOS GENERALES DE LOS VIAJES ESTUDIADOS. (Se incluye el gasto por persona, excepto en los viajes 3 y 4 de Aguilar que es el gasto de dos)

\begin{tabular}{c|c|c|c|c|c}
\hline Día & 1 Aguilar & 2 Aguilar & 3 Aguilar & 4 Aguilar & 5 Aguilar \\
\hline 1 & 26 & 18 & 46,5 & 43,7 & 21,7 \\
2 & 27,8 & 20 & 44 & 49 & 23,9 \\
3 & 29 & 30 & 43,5 & 42,5 & 21,7 \\
4 & 25,5 & 24 & 42 & 45 & 20,8 \\
5 & 82,3 & 20 & & 59,2 & 21,4 \\
6 & 27 & & & 35,2 & 21,2 \\
7 & 19,5 & & & 40,7 & 20,2 \\
8 & & & & 44,8 & 20,6 \\
9 & & & & 51,9 & 21,4 \\
10 & & & & 37,8 & 20,2 \\
\hline
\end{tabular}

Los viajes a Aguilar y el viaje a Salamanca dan una buena idea de los gastos diarios más comunes en este tipo de viajes. Los gastos regulares de cada día incluían el salario del viajero (6 maravedíes) y el coste del alquiler de la caballería (5 maravedíes), junto a los gastos de comida y posada (aproximadamente 11 maravedíes).

No hay relación diaria de los viajes de más larga duración a la corte del papa y del rey de Aragón, pero el viaje a Perpiñán en concreto ofrece una buena idea de los gastos imprevistos o extraordinarios que son los que anota el viajero. En el viaje a Perpiñán se encuentra también una breve referencia al costo medio de comida y posada: la mula necesitada del orden de un almud o almud y medio de cebada cada día, y el viajero pan, vino, carne y adobo de cocina, lo que, junto al pago de la posada, suponía aproximadamente cuatro sueldos y tres dineros de moneda aragonesa ${ }^{11}$. El gasto total de estos viajeros fue de veinte florines, lo que cambiado a moneda castellana suponía 1.020 maravedíes. Esto indica que el gasto medio por persona y día era muy similar al de los otros viajes más cortos: 18'9 maravedíes.

1 "Iten esta es la costa que yo el dicho Gonçalo FerRandes fasia yo e la mula un día con otro primeramente fasia la mula de costa un día con otro de çevada almut e medio que costava el almud dies dineros en que monta cada día quinse dineros Iten de paja un día con otro dos espuertas que costava seys dineros Iten de posada a mi e a ella cada día ocho dineros Iten de pan para mi un día con otro çinco dineros Iten de adobo de cosina un dinero Iten de tabla un dinero Iten de candelas un dinero en que monta esta costa de cada dya a mi e a la mula quatro sueldos e tres dineros". 
Lo que hemos considerado gasto medio por persona y día era la cantidad que costaba el mantenimiento del viajero y su caballería. Los gastos cotidianos eran el pan y el vino, junto a la carne, el pescado u otra fuente de proteínas, la cebada y la paja para las caballerías y el pago de la posada. Las cantidades que se empleaban en cada uno de estos capítulos queda reflejado en el siguiente cuadro.

CUADRO 4

CANTIDADES EN MARAVEDÍES DE LOS GASTOS COTIDIANOS MÁS IMPORTANTES DE UN VIAJERO

\begin{tabular}{c|c|c|c|c|l}
\hline Viaje & Pan-vino & Carne-pescado & otros alim. & Posada & Forraje \\
\hline 1 Aguilar & 38,5 & 31,7 & 7 & 15,5 & 44 \\
2 Aguilar & 22,5 & 18 & 2,5 & 11 & 29,7 \\
4 Aguilar & 83,5 & 32 & 21 & 18,5 & 59 \\
Salamanca & 40 & 30,5 & 9 & 15 & 37,5 \\
\hline
\end{tabular}

Los porcentajes empleados en cada uno de esos capítulos se expresan con claridad en el siguiente gráfico.

VIAJE A AGUILAR 4 (mayo 1415) ${ }^{12}$

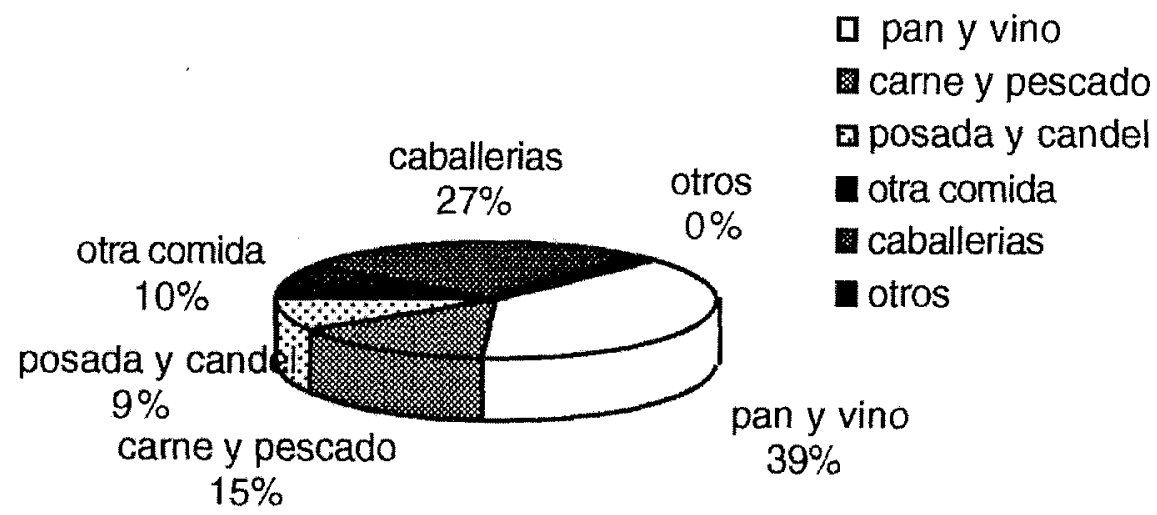

12 La elaboración de los gráficos se ha realizado mediante una pequeña base de datos introducida en el programa informático Excel 4.0. 
Los gastos más importantes eran los de pan y vino y mantenimiento de las caballerías, seguidos de la adquisición de carne y pescado. En el gráfico se han considerado solamente los gastos cotidianos, excluyendo el salario del viajero y el alquiler de la caballería. El gasto de vino era, a veces, extraordinario, pues no se limitaba a la bebida de los viajeros, sino que éstos tenían que hacer invitaciones. También excepcionalmente el gasto de comida se elevaba si en vez de comer solos, lo hacían a escote en la posada con otras gentes que en ella se encontraban ${ }^{13}$.

En el cuadro anterior no se han incluido gastos de otra índole que elevaban el costo de los viajes. Dejando a un lado el pago de "costas judiciales", es decir, de los derechos que habian de recibir los notarios, protonotarios, chancilleres o vicechancilleres, etc., por su trabajo, había otros gastos que no estaban previstos y que eran, si no importantes, al menos curiosos.

Algunos de estos pagos se hacian para conseguir el apoyo de personas con cierta influencia para que ayudaran a aligerar los procesos. En el primer viaje a la corte del Papa y del Rey de Aragón, Gonçalo Ferrnandes Ollero, gasta en una invitación al sobrino de vicechanciller quince sueldos y medio ${ }^{14}$. En el viaje a Salamanca, Juan Ferrandes invitó a merendar al mozo del bachiller «porque le rogase que me despachase de la çibdad».

También constituían gastos extraordinarios otras partidas como el pago a los guías que les ayudaban a cruzar un puerto o a seguir un camino poco conocido. Este solía ser el caso de los viajes al reino de Aragón, en los que también tenian el gasto extraordinario de pagar aduanas ${ }^{15}$. En las aduanas pagaban también por pasar las caballerías, aunque las cantidades fueran pequeñas: cuatro maravedíes costó inscribir el rocin en S. Esteban, y otro tanto "costo un testimonio signado en el Burgo que fis escribir la mula». Pero, a veces, estas inscripciones no tenían validez, y tenían que pagar dos veces. Esto les ocurrió una vez, que

13 El 21 de enero de 1415 cenaron en Castrillo de Villavega "con unos farruqueros e copo nos de escote çinco maravedies e çinco dirieros", una cantidad bastante superior a la que hubieran gastado de haber cenado solos.

14 «Iten dy al dicho sobryno del dicho viçechançeller por que me la fesiese signar media dosena de perdyses e tres conejos que costaron el par de las perdises a tres sueldos e medio e el conejo a veynte dineros en que monta todo quinse sueldos e medio".

15 El mencionado Gonçalo FerRandes OLlERo, incluye entre sus gastos del primer viaje a entrevistarse con el Papa, los siguientes: "a Ferrando de Palençia que tenía el puerto de las Sacas de ,Çirya porque non me enbargase el roçyn ni me catase un floryn", «Yten dyl de çevada a el e a sus omes porque me posieron allende del mojon de Aragon e costo pan e vino e carne medio floryn" 
les obligaron a hacer una segunda inscripción en Soria, porque la de El Burgo no valía ${ }^{16}$.

Aunque extraordinarios, los gastos de las costas judiciales o los de guias y aduanas eran previsibles. Pero el viajero se iba a encontrar con verdaderos imprevistos: en el cuarto viaje a Aguilar, los viajeros tuvieron que hacer frente a un embargo que les hicieron los alcaldes de esa localidad a requerimiento de los escribanos de la villa, en uno de los viajes a Aragón tuvieron que sangrar a la mula «de los paladares que non podía comer», y en Perpiñán se les perdió la mula. Recuperarla costó tres sueldos "al pregonero porque la pregono», dos florines al portero de la Reina "que me mostró el que fallo la mula e la tenia e abeni con el porque la mostrase e non se perdiese» y otro medio florín «al que la fallo porque la preso e me la diese». No faltaban gastos en otras menudencias como los quince dineros que pagaron por "una olla que quebro", en uno de los viajes a Aguilar ${ }^{17}$.

Las cantidades que recibía el viajero por su trabajo eran pequeñas, los seis maravedíes diarios debían considerarse un pago no muy gratificante, pues ninguno de los viajeros demuestra interés en que la estancia se alargue más de lo estrictamente preciso. De ahí que en ocasiones paguen «invitaciones» o «regalos» para aligerar el proceso, y poder regresar a casa lo más pronto posible. Arriba se ha citado el ejemplo del viajero a Salamanca, Juan Ferrandes, que pagó una invitación al mozo del bachiller para que «me despachase de la çibdad». Por otra parte, esa era la cantidad que normalmente se pagaba a los mensajeros que realizaban este tipo de trabajos, menor que la que recibían otros trabajadores por servicios de otra índole. Un obrero, por ejemplo, cobraba, en la segunda década del siglo, siete maravedíes por trabajos de construcción.

\section{LA VIDA COTIDIANA REFLEJADA EN LOS VIAJES}

Uno de los aspectos más interesantes de las cuentas de viajes es el reflejo que en ellas aparece de la vida cotidiana, en concreto de las costumbres en relación con la comida y la posada, los dos elementos imprescindibles en un viaje.

\footnotetext{
i6 "costo otro testimonio en Soria porque dixo Diego Alfons cavallero quel testimonio que avia tomado en el Burgo que non valia nada e que escriviese en el aduana ally la dicha mula que costo çinco maravedies"

17 Libro de Cuentas del mayordomo de PAREDES, 6 junio 1415.
} 
Lo primero que llama la atención al estudiar estas cuentas de viajes, es la importancia del pan y del vino en el desarrollo del viaje. Ya hemos indicado anteriormente cómo el gasto más elevado que realizaban diariamente era el de la compra de pan y vino, lo que no era de extrañar, pues no sólo en todas las comidas, sino en camino o en las paradas, el pan y el vino eran fundamentales ( $E$ eche en el barril de vino blanco para levar por el camino para bever çinco maravedies» ${ }^{18}$ ). La función del café y el té en los viajes de la sociedad contemporánea, la realizaban entonces el pan y el vino, de manera que no sólo se paraban los viajeros a beber vino y comer pan, sino que en los mesones, acompañarian las charlas y encuentros con otros caminantes con una jarra de vino.

El número de comidas que realizaban eran dos. En las cuentas estudiadas aparecen algunos días menciones a tres comidas, y excepcionalmente una cuarta, la merienda. Las comidas que recibían un nombre específico eran el yantar, la cena y la merienda, aunque en muchas ocasiones las menciones a la comida se limitan a comida "de mañana» o comida por la noche.

¿No había desayuno? Posiblemente no. En las anotaciones de gastos no aparece ninguna mención especial a tomar alimento por la mañana, exceptuando, claro está, pan y vino. Cuando el viajero come antes de salir, es porque sale ya bien entrada la mañana. Al inicio de un viaje ${ }^{19}$, antes de comenzar el camino, dicen «armosemos», y, en efecto, ese día no hacen mención de otra comida en el viaje, sólo de la llegada a la posada por la noche. El desayuno no se habia instaurado todavía como una costumbre ${ }^{20}$, de manera que la primera comida del día no se realizaba hasta mediodía. Las doce, la hora de «nona», cuando el hombre había cumplido con sus devociones, era el momento mejor para la principal comida del día. Evidentemente, los viajeros acomodarían esa comida principal del mediodía a una hora que les fuera factible para ellos, de manera que no necesariamente sería a las doce. Sin embargo, las jornadas de viaje antes indicadas, hacen pensar que, en efecto, el viajero se pararía a comer tras unas horas de viaje en la mañana, y después de comer continuaría la jornada, que se hacía más corta en invierno, y se alargaba y necesitaba partir, al acercarse el verano. Las diversas

\footnotetext{
18 Viaje a Aguilar, 19 junio 1415.

$19 \quad 16$ enero 1415

20 Para una discusión acerca del desayuno, Bridget A. Henisch, Fast and Feast. Food in Medieval Society, University Park and London, 1976, cap. 2 «Mealtimes", pp. 17-27.
} 
paradas en el viaje a Salamanca se deberían a la necesidad de tomar algún alimento, ya que al amanecer más temprano, y comenzar la marcha antes, el camino hasta donde tomaran las «doce» se haría muy largo. Por otra parte, ya avanzado el siglo XV, se iba imponiendo la necesidad de permitir a los trabajadores parar para tomar algunos «tentempiés».

En ocasiones, además de la cena, volvían a comer antes de ir a dormir. Podría ser el «reresoper», lo que B. A. Henisch denomina como la costumbre medieval, desaconsejada y denostada, de volver a comer o a tomar otra cena antes de ir a dormir ${ }^{21}$.

Fuera cual fuese el número de comidas y su distribución horaria, siempre hacían dos comidas fuertes al día, en las que ingerían el mismo tipo de alimentos, a veces, repetidos exactamente igual ${ }^{22}$ : pan y vino siempre, junto a algún alimento proteínico, normalmente carne, a veces pescado o huevos. Las frutas y verduras aparecen más raramente, pero también se encuentran de vez en cuando. Sólo era diferente la merienda, cuando la hacian, pues consistía en algún tipo de fruta o frutos secos y vino. Para conocer la alimentación diaria de un viajero, puede servir de ejemplo la siguiente anotación:

«Primeramente este dicho día armosemos e costo un quartillo de cordero quatro maravedies.

Iten fuemos por Famusco por estar con el arçipreste para que nos diese una nibiçion para faser otra por ella e non le fallamos. E fuemos dar çevada a Fromesta e costo un pan un maravedi.

Iten de vino a seys maravedies el açumbre dos maravedies

Iten un çerrero de paja e un çelemin de çevada dos maravedies

Iten fuemos a dormir a Santa Yllana este dia e fesimos de gasto de pan e carne tres maravedies

Iten de vino quinse dineros...»

Uno de los viajes a Aguilar puede servir para dar una idea de la alimentación en el transcurso de todo un viaje, exceptuado el pan y el vino, que estaban siempre presentes en la mesa, y a lo largo del camino.

21 Ibidem, p.17.

22 El sistema de las dos comidas diarias sin apenas variación estaba extendido en toda la Europa medieval, tal como indica E. KISBAN, «Food habits in change: the example of Europe", en A. FENTON y E. KISBÁN (editores), Food in change, Eating Habits from the Middle Ages to the Present Day. National Museum of Scotland, 1986. 
CUADRO 5

DIETA ALIMENTARIA DEL VIAJE A AGUILAR DE MAYO DE 1415

\begin{tabular}{l|l|l}
\hline \multicolumn{1}{c|}{ Día } & Alimentos comida mañana & \multicolumn{1}{c}{ Alimentos comida tarde } \\
\hline jueves 9 & una libra de carnero & huevos e manteca \\
viernes 10 & peçes & huevos e un queso asadero \\
sábado 11 & huevos e un queso asadero & huevos e manteca \\
domingo 12 & carnero, toçino e verças & carnero \\
lunes 13 & 2 libras carnero e verças & un quartillo cabrito \\
martes 14 & 2 libras carnero e toçino & libra e media de carnero \\
miércoles 15 & huevos e manteca & huevos e manteca \\
jueves 16 & carnero e toçino e perexil & 2 libras e media de carnero \\
viernes 17 & pescado e aseyte e salsa & lechugas, porretas, vinagre \\
sábado 18 & libra e media de peçes & huevos \\
\hline
\end{tabular}

La repetición de los mismos alimentos en las dos comidas venía, sin duda, impuesto por lo que se les ofrecía o encontraban en las localidades en las que paraban, aunque había veces que llevaban la comida. Al iniciar el viaje a Palencia, el 26 de enero de 1403, llevan un congrio fresco que habían comprado en Paredes antes de salir. Unos días después, el jueves 1 de febrero, estando en Medina, compran poca cantidad de carne, porque «sobro carne del miércoles».

Si en los «menús» diarios no hay una mínima preocupación por hacer una dieta equilibrada, si aparece la preocupación por la observancia del precepto eclesiástico de no comer carne los viernes y los sábados. En todos los viajes estudiados se mantiene estrictamente la observancia, o al menos de la forma que ellos entendían el rigor. Sin embargo, en la dieta de estos viajeros para los días de abstinencia, se puede observar el inicio del declive del excesivo rigor religioso en el cumplimiento de las regulaciones sobre ayuno y abstinencia. Hasta principios del siglo XV, la Iglesia prohibía en miércoles, viernes, sábado y durante toda la Cuaresma, comer carne, manteca, huevos, leche, mantequilla y queso ${ }^{23}$. En la primera mitad del siglo XV comienza a percibirse un cambio en este cumplimiento religioso, y se observan diferencias significativas en espacio y tiempo. Mientras en unas partes de Europa se mantenía la rigidez respecto al precepto eclesiástico, en otras las costumbres eran menos estrictas. En el

23 E. KISBÁN, "Food habits in change...", p. 3, indica el inicio de variantes locales (o regionales) en la observancia del precepto religioso de la abstinencia, desde comienzos del siglo XV. Esas quedan patentes al compatar los viajes de los enviados paredeños con el viaje Desde Estella a Sevilla, pues en este recorrido, a mediados del siglo XIV, sólo observaron el viemes. 
área castellana en que se movían estos viajeros, el rigor se había perdido, y únicamente mantenían la abstinencia de comer carne los viernes, sábados y días de Cuaresma. Huevos, leche, queso y manteca no se encuentran entre la dieta de abstinencia de estos viajeros ${ }^{24}$.

A principios del siglo XV, la abstinencia en miércoles aun se mantenía en algunos lugares. En el viaje a Medina un miércoles compraron huevos y manteca «para los que non comieron carne». Cuando en 1402, seis vecinos, entre los que iba el corregidor, viajaron a Palencia un miércoles, compraron tres gallinas, pero también «un besugo para los que non comían carne». El caso contrario, sin embargo, también se da, un sábado en Medina compraron "una polla para el que no comió pescado». La abstinencia en miércoles ya no la cumplían a mediados del siglo XIV los viajeros que hicieron el citado viaje de Estella a Sevilla. La rigidez en el cumplimiento eclesiástico podría observarse a través de las manifestaciones del arte medieval ${ }^{25}$.

Los tipos y calidades de alimentos que se encuentran citados en estos viajes son diversos. El vino, blanco o tinto, y, a veces, añejo, se vende a precios muy diversos, lo que podría depender de su calidad. La carne más común era la de carnero, pero también se consumía con cierta frecuencia la de cordero, cabrito, pollo, gallina, vaca o ternera, sin faltar menciones al tocino, la marrana o la asadurilla de cordero; también aves y caza, como perdices o conejos. Los pescados de los que hay mención en los citados viajes son de mar y de río, salados y frescos: besugo, congrio, sardinas, truchas, pescado seco y peces. Las verduras y frutas más comunes eran las de temporada: lechugas, porretas, puerros, espinacas, limas, berzas, rábanos, nabos, cogombros, aceitunas, manzanas, higos o cerezas, no faltando menciones al perejil, los ajos, o frutos secos como avellanas, almendras y nueces. Las especias que utilizaban eran la mostaza, la sal y la pimienta. Otros alimentos que consumieron en un momento $u$ otro fueron

24 La única cita a la compra de leche se encuentra precisamente el viernes 21 de mayo de 1415. La leche se consideraba más bien una bebida de entermos, de ahí que raramente aparezca entre las menciones de alimentos que se encuentran en estos viajes. Como en el viaje de vuelta de Sevilla a Estella, uno de los viajeros enferma, hemos comprobado si por ello adquirían leche, pero no es asi, las únicas menciones a compras especiales para el enfermo son sólo dos: "Costo açuquar pora Gil Garcia 2 maravedis" y "costaron halmendolas pora Gil Garcia 6 dineros". Desde Estella a Sevilla, pp. 79-80.

25 En las pinturas de la Santa Cena no siempre se representa el cordero pascual entre los alimentos, en algunas áreas o épocas son peces los que constituyen el alimento de la última cena. Esto puede verse en los frescos de S. Baudilio de Berlanga del Museo de Bellas Artes de Boston, en una tabla de un maestro umbro del Museo de Arte de Worcester, o en uno de los mosaicos de S. APOLINAR el Nuevo, entre otros. 
huevos, leche, miel, garbanzos, habas, aceite, manteca, vinagre y queso, en concreto el queso asadero que se cita arriba en el viaje a Aguilar de Campoo.

De la preparación y condimentación de los alimentos también hay alguna referencia. Ya se ha mencionado antes el uso de manteca para preparar los huevos; el aceite lo reservaban para preparar el pescado, de manera que sólo hay referencias a su adquisición los días que comían pescado; y hay continuas referencias al "adobo de cocina", que pagan en todas las posadas, mesones o tabernas en las que paran para comer o cenar.

No hay buena información acerca de las cantidades que tomaban de estos alimentos, aunque en algunos casos se especifica lo que comía diariamente cada viajero, tal como indicaba Gonçalo Ferrandes en su viaje a Perpiñán antes citado. Las raciones de pan y vino eran abundantes, pues ambos eran fundamentales en todas las comidas del día. La ración de pan era de un pan por comida y día, de manera que cuando compraban pan en una localidad por la que pasaban gastaban normalmente un maravedí para dos viajeros, por lo que le daban dos panes, ya que el precio del pan en aquellos años en la zona estudiada, era de medio maravedí cada pan o "porción de pan». Cuando en los viajes de 1403 compraban pan para todos los viajeros también la ración era de un pan por comida y día, es decir, dos panes diarios. Cuando fueron a Palencia diez viajeros compraron veinte panes para todo el primer día, aunque al día siguiente sólo compraron dieciséis. En el primer día de viaje a Medina, para veinte hombres compraron veinte panes para cenar.

El consumo de vino debía ser abundante también. Varias anotaciones pueden servir para hacernos una idea de la cantidad que consumian. En el viaje a Salamanca, al llegar a Puente de Duero, el viajero compró medio azumbre para cenar, y al llegar a Valladolid a la mañana siguiente compró otro medio azumbre. Pero ese día no se conformó con el medio azumbre, sino que además gastó un maravedí de vino en Ampudia, y otro más en Paredes al llegar. En el viaje a Aguilar que realizó Juan Ferrandes en mayo de 1415, compró medio azumbre de vino en Medianeda de Campoo, a dos leguas de Reinosa, y ese mismo día compró en Reinosa otro azumbre, y al día siguiente un "terçuelo" (tercio de azumbre). En los dos días siguientes compraron un azumbre en cada una de las dos localidades por las que pasaron, Aguilar de Campoo y Villavermudo. Calculando los precios del azumbre, se puede concluir que el vino que bebían diariamente era aproximadamente medio azumbre (un litro) por la mañana, y algo menos del litro por la tarde, pero con algunas paradas extras, superaría 
posiblemente los dos litros, lo que estaba a tono con el consumo de la época ${ }^{26}$.

La cantidad de carne que consumían diariamente variaba según el tipo de carne, la pieza que compraran (con o sin hueso), o simplemente de la cantidad disponible o incluso del gusto del viajero. Cuando compraban carne de carnero, la más común, lo hacían entre una libra y dos libras y media para los dos viajeros; como indicaba Gonçalo Ferrandes en el viaje a Perpiñán, «un día con otro» la ración media solía ser de una libra, aunque en otra ocasión indicaba que era sólo de media libra. Una vez que comieron ternera, adquirieron cuatro libras para tres personas. Cuando compraban crías, dos personas daban cuenta de un cuarto del animal ("un quartillo de cordero» o «un quartillo de cabrito»). Cuando eran más los viajeros compraban el animal entero. Esto ocurrió en el viaje a Medina, en el que para cenar adquirieron un cabrito y un par de perdices; esa mañana habían comido medio carnero. La carne de ave aparece en menos ocasiones. En el viaje a Aguilar de Campóo, de junio de 1415, el notario del pleito, Juan Carretero, junto al escribano Juan Sanches y Pedro pregonero, compraron un día una polla para una de sus comidas, otro día comieron y cenaron pollo, pues compraron dos para la comida en Castrillo y uno para la cena en Villavermudo. También hay mención a la gallina que compraron para el señor D. Fernando cuando estaban tratando con él en Medina.

Las raciones de pescado parecen ser menores, a juzgar por las cantidades que adquirían. Los peces, truchas o sardinas las compraban entre libra y libra y media, aunque no faltan referencias a adquisiciones mayores, como en una ocasión en que mercaron tres libras de peces para tres personas. Cuando se trata de un pescado grande lo compraban por piezas. Esto ocurre con el congrio o el besugo ${ }^{27}$; de este último pescado solían adquirir uno para dos viajeros.

De otros alimentos es difícil averiguar la cantidad que ingerían. Cuando se habla de verduras no se dice la cantidad, como tampoco lo indican cuando toman huevos ${ }^{28}$. Solamente hay una referencia a que compraron

26 Hay muchas referencias al consumo diario de vino en variedad de trabajos. Se podrian utilizar como ejemplos los de CH. JÉHANNO, "Boire a Paris au XV siecle: le vin a l'Hotel-Dieu», Revue Historique. 276, 1986.

27 En otra ocasión que se cita el salmón, también se menciona que se compra uno entero. Libro Cuentas del Procurador de Paredes de Nava, 5 marzo 1407.

${ }_{28}$ El número de huevos por comida es posible que fueran bastantes, tal como indica $P$. Martinez SOPENA y M.J. Carbajo en "L'alimentation des paysans castillans du Xle au XIlleme siecle d'après les "fueros", Manger et Boire au Moyen Age. Actes du Colloque de Nice (15-17 oct. 1982), 1984, p. 347; en la comida de la mañana ingerían cuatro huevos por persona. 
un queso asadero para una cena y otro para una comida, pero es una referencia muy vaga, pues se desconoce su tamaño o peso.

A través de las anotaciones de los viajeros se pueden conocer también los precios de los alimentos. La porción de pan, un pan, les costaba a medio maravedí en todos los viajes, tanto en los de Aguilar como en los de Salamanca. La uniformidad del precio del pan no se repite en el precio del vino. Entre las referencias de precios podemos señalar las siguientes:

\section{CUADRO 6}

PRECIOS DEL VINO EN ALGUNAS LOCALIDADES DE LOS ITINERARIOS DE AGUILAR DE CAMPOO Y SALAMANCA

\begin{tabular}{l|l|l}
\hline \multicolumn{1}{c|}{ Lugar } & Fecha & Precio/azumbre \\
\hline Puente de Duero & abril 1415 & 3 maravedies \\
Valladolid & abril 1415 & 3 maravedies \\
Medianeda Campoo & mayo 1415 & 3 maravedies \\
Reinosa & mayo 1415 & 3 maravedies \\
Aguilar Campoo & mayo 1415 & 2 maravedies \\
Villavermudo & mayo 1415 & 15 dineros \\
Aguilar Campoo & mayo 1415 & 2 mrs. y 5 din. \\
Reinosa & mayo 1415 & 3 mrs. y 5 din. \\
\hline
\end{tabular}

Estos precios del vino eran elevados con respecto a los precios que se pagaban en la propia localidad de Paredes de Nava. El azumbre costaba en Paredes entre 1412 y 1415 a un maravedí, subiendo algunos meses hasta 12 dineros, y a final del año 1414 hasta 10 cornados. Al comenzar el año 1415 se pagaba el vino añejo a dos maravedíes el azumbre ${ }^{29}$.

Las diferencias en el precio del vino (sin explicación en los documentos estudiados) podrían deberse a tipo o calidad. El vino blanco solía ser más caro que el tinto ${ }^{30}$.

Aunque los precios de pan y vino eran los más baratos, constituían el porcentaje más elevado de los gastos cotidianos de un viajero, por ser lo que más consumian. Con un maravedí podian comprar un pan o un azumbre del vino más barato (tal como se vendía en Paredes). Por un maravedí podían comprar también una asadurilla de cordero y algunos huevos.

29 Libro de Cuentas del procurador de Paredes de Nava, 31 de diciembre de 1415.

30 En un viaje que realizaron en 1415 a la localidad de Santa Cruz pagaron el azumbre de vino blanco a 3 maravedies, en tanto que el vino "colorado" les costaba justamente la mitad. 
Algo más caro le resultaba la libra de carnero, que costaba entre 7 (Carrión) y 8 cornados (Aguilar y Reinosa). Un "quartillo" de cordero les costó 4 maravedíes en Paredes de Nava y medio maravedí más en Aguilar de Campoo. El «quartillo» de cabrito valía la mitad que el de cordero, a 2 maravedíes. La única mención que se encuentra de la carne de ternera, la señala como la más barata, a un maravedí la libra. El pollo era caro en relación con las otras carnes, pues uno vivo costaba 3 maravedíes.

Los precios del pescado eran más elevados en general. El pescado más caro era el congrio, del que hay varias referencias en los viajes de 1403. Su precio variaba obviamente por su tamaño, pero aparece como el más caro de los pescados: en una ocasión pagaron por uno 32 maravedíes, otro les costó 17 maravedíes, y otro 15 . El precio del besugo variaba también con el tamaño, pero la oscilación de precio era menor: por uno pagaron en 1415 cinco maravedíes, y unos días después por otro cuatro; como es de suponer que su peso sería superior a las dos libras, su precio sería como máximo 2 maravedíes la libra. No eran, sin embargo los pescados más caros, pues otras referencias a compras de pescado, sin determinar cuál, indican que se pagaba a 3 maravedíes la libra. Había pescados menos caros, algunos incluso más baratos que la carne, como eran los peces o «pescado de rio" y las sardinas; en dos ocasiones aparecen citados, los primeros por 9 dineros (sin especificar cantidad), y las sardinas por 5 dineros (sin especificar cantidad tampoco). Aunque en los viajes estudiados no aparece mención a ello, en otra de las cuentas del procurador de Paredes de Nava hay una cita al que, sin duda, era el pescado más caro que se podía comprar entonces: el salmón. Por uno pagaron 150 maravedíes, probablemente porque el personaje al que iban a invitar lo merecía ${ }^{31}$.

Más difícil resulta conocer los precios de frutas, verduras o especias, pues aunque se indica lo que pagan, falta el dato de la cantidad que compran. Sin embargo, frutas y verduras resultaban en general bastante baratas.

Los precios citados son meramente indicativos de lo que le costaban al viajero esos artículos en los lugares que pasaban, pero hay que pensar que esos precios podrían estar hinchados para el forastero, y que no fueran los precios reales que se pagaban en esas localidades por los mismos artículos. Cualquier producto podría servir de ejemplo. Se podría elegir la cantidad que pagaron por un "quartillo» de cordero en Paredes de Nava y en Aguilar de Campoo. En Paredes costó cuatro maravedíes y en Aguilar

31 Libro Cuentas del procurador de Paredes de Nava, 5 marzo 1407. 
cuatro y medio. La diferencia podría deberse simplemente a que en Paredes se lo compran al carnicero conocido, con una tasa de precios fijada, y en Aguilar se lo compran a un carnicero que, o bien tiene una tasa fijada más elevada, o bien le hace pagar algo extra al forastero que no tiene otra opción, si lo quiere lo paga, o de lo contrario no lo tiene. Sin embargo, la carne era uno de los alimentos en los que había menos posibilidades de subir el precio, pues muchos concejos obligaban a los carniceros a respetar unos precios. En otros productos tendrian que aceptar los precios que quisieran los vendedores, quienes probablemente cobraran algo más a los forasteros.

Por último, en estos datos de viajes queda también constancia de que la comida era un medio de distinción social, es decir, dependiendo de la categoría de las personas, así se comía una u otra cosa. Las comidas consideradas como de más alto rango eran las perdices, conejos, aves o algunos tipos de pescado. Las menciones a perdices se encuentran raramente. En una ocasión se citan porque se les va a hacer como regalo al vicecanciller papal ${ }^{32}$. En los viajes citados de 1403 (en el primero fueron diez personas y en el segundo veinte), parece claro que no todos comían lo mismo, había diferencias según el rango. El primer dia, llevaban de Paredes un congrio fresco para cenar, pero después compraron «pan, vino e sardinas para los omes de pie". Al día siguiente adquirieron también dos tipos de pescado, congrio y sardinas, y aunque no indican porqué, hay que suponer que el congrio sería para los de más alto rango y las sardinas para los menos importantes. Otro día compraron un cabrito y un par de perdices, y como eran veinte no todos pudieron comer perdiz, probablemente este manjar fuera para los mismos que comian el congrio, y los demás comerían cabrito ${ }^{33}$. Otro día lo especifican claramente, pues también cenaron cabrito, pero compraron «una gallina para don Fernando", el conde señor de la villa, futuro rey de Aragón.

Estas mismas diferencias en las costumbres alimenticias de las distintas clases sociales son las que menciona $M$. T. Lorcin, al referirse al villano rico que, aunque tenga dinero, continua fiel a sus costumbres, y por tanto: «no comerán salmón ni perdiz ... pan y vino y huevos fritos, y

32 J. Carlos VizUeta, «La dieta alimenticia en la religiosidad femenina de $S$. Clemente de Toledo", indica cómo las perdices eran sólo para la abadesa, p. 250.

33 A. RUCQUO1, "Alimentation des riches, alimentation des pauvres dans une ville castillane au XVe siecle", Manger et boire au Moyen Age, Actes du Colloque de Nice (15-17 oct. 1982), 1984, pp. 297-312, indica como la carne era para los pobres de la cofradia que ella estudia en el artículo, y como las aves estaban en la cumbre de la jerarquia de los placeres de mesa. 
queso" comerán ${ }^{34}$. En efecto, la mesa bien provista debe contener viandas entre las que no falten las aves. En este sentido, también el arte y la literatura son dos fuentes de primer orden para entender los valores del hombre medieval respecto a lo que se consideraba una buena comida 0 un buen banquete ${ }^{35}$.

\section{LA POSADA Y EL MESÓN}

La comida de los viajes se compraba, cocinaba e ingería en algún establecimiento del camino, posada, mesón o en alguna casa que se prestara para ello. En ellos tenían que buscar donde dormir y donde dar de comer a las caballerías. Los datos ofrecidos por los viajeros, no sólo de los viajes estudiados sino en general, no son significativos como para iluminar el tema de la «hostelería» medieval, lo que ha podido ser una de las razones de la falta de atención de los historiadores, que lo han tratado como "materia pintoresca en una historia anecdótica de la vida cotidiana» ${ }^{36}$.

A la hora de estudiar los lugares de descanso en el camino, se plantea un primer problema al tratar de definir la naturaleza de los establecimientos en los que comiar, y descansaban. En algunas de las paradas hacen mención explícita de residir en una posada («gastemos a medio día con los alcalldes que nos enbargaron la posada» ${ }^{37}$ ), pero en otras ocasiones se limitan a decir "comimos" o "dormimos", sin mencionar dónde. Si en sus estudios sobre la hostelería medieval francesa, Noel Coulet ha

\footnotetext{
34 M. T. LoRCIN, "Manger et boire dans les fabliaux: Rites sociaux et hiérarchie des plaisirs", Manger et boire au Moyen Age. Actes du Colloque de Nice (15-17 oct. 1982),1984, pág. 230.

35 En el "infierno" que representa Taddeo di Bartolo en los frescos de la colegiata de $S$. Gmlignano, aparece la imagen de una mesa bien provista de pan, vino y un ave, que se presenta como un tormento para los condenados, porque agarradas sus manos por los demonios, pueden ver la mesa muy cerca, pero no pueden acceder a los alimentos. En el famoso cuadro "Los siete pecados capitales". EI Bosco representa la gula con la imagen de un hombre comiendo la pata de un ave, sobre la mesa aparece servida una pata de animal, un costillar de cordero, pan, vino, y una criada entra trayendo un ave. La literatura castellana de la Baja Edad Media ofrece ejemplos interesantes de lo que se consideraba buena comida. Una relación significativa de las obras en las que se encuentran citas de la comida se encuentra en J. L. MARTíN, "Simbolismo y comportamiento en la mesa", Historia 16, 223, nov. 1994, pp. 67-85.

36 Así lo indican N. COULET, "Les hotelleries en France et en Italie au Bas Moyen Age", L'homme et la route on Europe occidentale au Moyen Age et aux Temps modernes, Deuxiemes Journées intemationales d'histoire, 20-22 sept. 1980, Auch, 1982, p. 182, y J.A. CHARTRES, "Les hotelleries en Angleterre a la fin du Moyen Age et aux temps modernes", L'homme et la route en Europe occidentale au Moven Age ..., p. 207.

37 Viaje a Aguilar, 17 de mayo de 1415.
} 
señalado la diferencia entre albergue y taberna ${ }^{38}$, en la documentación castellana también se hace una distinción entre mesón y posada («posadas que no sean mesones" ${ }^{39}$ ). María del Carmen Carlé ha explicado el concepto de "posar" como no necesariamente vinculado a un establecimiento público o posada ${ }^{40}$.

Los viajeros de los viajes estudiados no se refieren nunca a una posada o a un mesón en particular, al aparecer anotados sus gastos en las cuentas. Solamente se indica lo que se paga de posada como un concepto general, de manera que tanto podría entenderse que utilizaron un establecimiento preparado como tal, o una casa ${ }^{41}$.

Aunque se puede pensar que posadas y mesones serían en buena medida privilegio de las ciudades, villas o lugares grandes, sin embargo, la posada no era monopolio de la ciudad. En los pueblos pequeños habría una posada o simplemente una casa que se consideraba la posada, a la que dirigían a todos los forasteros que preguntaban por un lugar para descansar, comer o dormir. En realidad muchas posadas o mesones no eran más que casas normales, que el propietario amueblaba en función de ser utilizadas para albergar a viajeros ${ }^{42}$. En la propia localidad de Paredes de Nava se encuentran menciones en la documentación a pagos realizados a vecinos por "posar» algún personaje forastero en su casa ${ }^{43}$.

Una breve indicación puede llevar a pensar en la existencia de posadas en los lugares algo más grandes, y en la utilización de casas en los más pequeños. Cuando paran en Aguilar de Campoo, Carrión, Reinosa,

38 La distinción entre posada, mesón y tabema no parece estar bien delimitada. Si ej mesón y la posada eran lugares especialmente pensados para pernoctar, la taberna parece serlo para beber o comer, sin embargo, en algunas tabernas también se pernoctaba. N. CouLET, "Les hotelleries en France et en Italie au Bas Moyen Age», pág. 186.

${ }^{39}$ En las cuentas del procurador de Paredes de Nava se encuentra la mención a los hombres del corregidor, que habitaran en casas o posadas "que no sean mesones", 28 mayo de 1423.

40 M. C. CARLÉ, «La casa en la Edad Media castellana», Cuadernos de Historia de España, LXVII-LXVIII, 1982; p. 204 y ss.

41 El silencio de los viajeros acerca de los establecimientos en los que se albergaban era bastante normal, como señala N. COULET, "Les hotelleries en France et en Italie au Bas Moyen Age", p. 182.

42 N. COULeT señala la existencia de albergues de viajeros en pequeñas localidades de la región de Aix-en-Provence, art. citado, p. 187, y «Un gite d'etape: les auberges a Aix-en Provence au quinzieme siecle", Actes du colloque c.u.e.r.m.a. 1976 Voyage. Quete. Pelerinage dans la litterature et la civilisation medievale, Aix-en Provence, 1976, pp. 107-124.

43 Libro Cuentas del procurador de Paredes de Nava, 1 junio 1417: «pague a la mujer de Juan Maestro de posada que poso este Gonzalo Ferrandes este camino en su casa», unos días después, el 19 de junio el mayordomo indica: «pague a Juan Sanches yerno de Juan Cerbatos de su posada que poso en su casa Garcia Alvares de Carrion recabdador de la merindat de Carrion". 
Salamanca, etc. hablan de posada. Cuando paran a dormir en Castrillo de Villavega, en el camino de los viajes a Aguilar, dicen: "de leña que dymos a la huéspeda» o "de posada a la huéspeda». A esta "huéspeda» le pagaban 5 dineros, es decir, medio maravedí, cuando en otros viajes normalmente pagaban de posada un maravedí por persona y noche. En el itinerario citado de Estella a Sevilla se indica que los viajeros paran en casas y son atendidos por las «huéspedas», raramente se hace mención a posadas o mesones ${ }^{44}$.

La posada se utilizaba fundamentalmente para dormir, o al menos la mayor parte de los huéspedes llegaban para pernoctar y partir a la mañana siguiente. El precio de la posada variaba según los servicios que utilizaran los viajeros. La posada «de mesa», que utilizaban a veces para tomar el yantar, les costaba medio maravedí, en tanto que por pernoctar pagaban un maravedí por viajero y día, aunque en ese precio se incluía también la estancia de la caballería. En el viaje a Perpiñán distinguen entre «tabla» $y$ "posada», refiriéndose con el primer término al pago de mesa para comer y el segundo a la cama. En el maravedí que pagaban diariamente por dormir o "de tabla» o "posada de mesa» estaba incluido el servicio de las mujeres que cocinaban, servían o limpiaban en la posada, aun que no faltan casos especiales como cuando indican que «partimos de Aguilar e dymos a la moça que nos adobava de comer dos maravedies". No estaba incluido el alumbrado, pues el viajero llevaba consigo las candelas, gasto que indican también diariamente.

Las posadas y mesones daban comidas. Aunque algunas vendían comida y bebida 45 , a veces el propio viajero llevaba los alimentos, como queda de manifiesto cuando Juan García de Paredes estuvo en la villa de Paredes de Nava en el año 1403, y compraron viandas a distintos vendedores de la localidad para llevarlas a la posada, donde las prepararian. Aunque compraran la comida en la posada, en las cuentas se indica separadamente el gasto de comida del gasto de posada. No siempre utilizaban la misma posada para cenar y dormir, de hecho en algunos viajes se paran a cenar en algún mesón, taberna o casa, y luego continuan la jornada para dormir en otra posada.

La posada era, sin duda, centro de vida social, donde se encontraban con viajeros de otras partes, con los que, a veces, compartían mesa, comida, bebida y conversación. Algunas noches se reunian con algunos de

44 Maria Desamparados Sanchez Villar, Desde Estella a Sevilla...

45. P. W. HAMmond, Food and Feast in Medieval England, Alan Sutton publisher, 1993. 
sus compañeros y pagaban a escote la cena, lo que generalmente ascendía el precio de lo que habían de pagar. Se consideraban más bien lugares para las clases populares, de manera que los personajes de más alto rango no solían frecuentar estos establecimientos en sus viajes, sino que utilizaban los palacios, mansiones, monasterios, $u$ otros lugares considerados más dignos ${ }^{46}$.

La posada como centro de marginalidad y criminalidad no aparece reflejado en la documentación manejada, aunque la picaresca no debía faltar en algunos de los lugares frecuentados. El hecho de que en una ocasión denunciaran a la "huéspeda" es señal de que algún problema se les planteó. Sin embargo, es posible que la criminalidad y marginalidad frecuentes en mesones y tabernas, fuera más propio de lugares grandes, en los que los maleantes se refugiaran ${ }^{47}$. En los viajes estudiados en este artículo sería menos normal encontrar a este tipo de personajes en una pequeña posada de pueblo, o en la casa de alguna mujer que ofrecía una habitación para dormir o su cocina para preparar la comida del viajero.

\section{CONCLUSIÓN}

«Con pan y vino se anda el camino» es un refrán castellano que tiene una base real: el pan y el vino eran fundamentales en los caminos de los viajeros de tiempos pasados, en concreto de la Edad Media. Pero no sólo encontramos su importancia en Castilla o el área hispana, sino que debía ser algo general a los viajeros europeos de aquellos tiempos. En el libro clásico de J.J. Jusserand, Les Anglais au Moyen Age, descripción de la vida de los caminantes ingleses del siglo XIV ${ }^{48}$, se pueden ver algunas características de los viajes medievales que coinciden en todos los ámbitos de Europa. Utilizando como ejemplo el viaje de dos colegiales del Merton College con cuatro sirvientes, de Oxford a Durham y Newcastle, en 1331, llega a conclusiones que hemos apuntado en los viajes de esos viajeros castellanos estudiados arriba. Viajaban a caballo, su comida era muy simple, casi todos los días lo mismo. El pan, la cerveza y el vino constituían el gasto diario más importante, seguido de la carne. También pagaban por

\footnotetext{
46 M. C. Carlé, op. cit. p. 206.

47 B. GEREMEK, Les marginauX parisiens auX XIVe et XVe siecles. París, 1976, pp. 114-5, 170 y ss.

${ }_{48}$ Se ha utilizado la reciente reedición en lengua inglesa, J.J. JuSSERAND, English Wayfaring in the Middle Ages (XIVth century). Boston, 1979.
} 
las camas de la posada y las velas que tenian que llevar. Las únicas diferencias eran que la cerveza era muy importante en ese área europea, y no en Castilla, y el pan era mucho más caro, costándoles el doble que les valía la posada, en tanto que en Castilla la proporción era inversa, el pan les costaba bastante menos que a ellos, y también menos que la posada.

No cabe duda de que el mundo de los viajeros medievales merecería una atención mayor de la que ha tenido hasta ahora, pues sus noticias constituyen una buena fuente de conocimiento, por un lado de aspectos ordinarios de la vida cotidiana, y por otra de aspectos extraordinarios de las sorpresas que aguardaban al viajero en las rutas por las que circulaba. 